\title{
Projeto Dia do Orgulho Negro: uma experiência de saúde antirracista na Atenção Básica
}

DOI: : https://doi.org/10.5935/1984-9044.20200012

\author{
Igor do Nascimento Mesquita ${ }^{12}$ - Universidade Estadual de Campinas (UNICAMP)
}

Resumo: Este trabalho relata uma experiência de intervenção, na perspectiva da promoção da saúde, denominada "Dia do Orgulho Negro", construída pela comunidade com uma UBS em Campinas e com apoio intersetorial. Buscou-se enaltecer elementos culturais da população negra, através de apresentações, oficinas e tendas, destacando o potencial dessas ações como estratégias para despertar pertencimento identitário e fortalecimento de vínculos, visando a produção de identidade negra positiva e combate ao racismo. É traçado um breve panorama do lugar do negro na cidade de Campinas e a relação da psicologia com o racismo. Como resultados, foi possível sensibilizar os profissionais para a importância de considerarem os efeitos do racismo institucional no processo de saúde, possibilitar maior aproximação entre a UBS e a população negra do território e construção de pauta de ações intersetoriais com foco no racismo institucional. Conclui-se com provocações e apontamentos frente a um desejo de um projeto de saúde antirracista.

PALAVRAS-CHAVE: saúde mental da população negra; psicologia; racismo; promoção da saúde.

\section{Black Pride Day Project: an anti-racist health experience in primary care}

Abstract: This work reports an intervention experience, in the perspective of health promotion, called "Black Pride Day", built by the community with a BHU in Campinas and with intersectoral support. We sought to highlight cultural elements of the black population, through presentations, workshops and tents, highlighting the potential of these actions as strategies to awaken identity belonging and strengthen bonds, aiming at producing positive black identity and combating racism. A brief overview of the place of the black in the city of Campinas and the relationship between psychology and racism is outlined. As a result, it was possible to sensitize professionals to the importance of considering the effects of institutional racism in the health process, to enable a closer relationship between the $\mathrm{BHU}$

\footnotetext{
${ }^{1}$ Psicólogo, Especialista em Saúde Mental no Formato de Residência Multiprofissional - Universidade Estadual de Campinas (UNICAMP). ORCID: https://orcid.org/0000-0002-3183-787X

${ }^{2}$ Artigo baseado no Trabalho de Conclusão de Curso do autor, sob orientação de Bruno Ferrari Emerich
} 
and the black population of the territory and the construction of an agenda of intersectoral actions focusing on institutional racism. It concludes with provocations and notes regarding a desire for an anti-racist health project.

KEY WORDS: mental health of the black population; psychology; racism; health promotion.

\section{Introdução}

A

sociedade brasileira, no âmago da sua estrutura, foi formada com pilares da ideia de superioridade racial do branco. A matemática histórica do Brasil é perversa e sanguinária no que tange à categoria étnico-racial: são mais de 500 anos do processo de genocídio dos povos indígenas e mais de 300 anos de escravidão dos povos negros. As marcas dessa herança de desigualdade racial perpetuam-se fortemente até os dias atuais e ressoam em todas as facetas da esfera social, mas também deixam evidente a necessidade de luta e de atuação política contra tais iniquidades em todos os setores da sociedade. Portanto, é gritante e necessário assumir: o Brasil é um país estruturalmente racista.
Segundo Almeida (2019), o racismo decorre de como a sociedade se estrutura baseando-se em princípios discriminatórios de raça, e assim normaliza e concebe como verdade determinados padrões e regras. O autor pontua que o racismo é parte de um processo histórico, social e político que elabora mecanismos para que grupos sejam discriminados sistematicamente. É a partir de uma determinada ordem social estabelecida que o racismo moldase e estrutura-se na sociedade e, embora tenha várias facetas e diferentes manifestações, o racismo é sempre estrutural. Para o autor, é impossível analisar o racismo sem levar em conta a sua relação intrínseca com outros elementos da vida social, como a economia, o direito e a política. Acrescentamos aqui a saúde como outro 
importante elemento social com o qual o racismo também se relaciona.

Em se tratando do Brasil, Munanga (2017) problematiza a ambiguidade do racismo à brasileira e aponta essa característica como um dos entraves na efetiva luta contra o racismo. O autor pontua que o racismo no Brasil é um crime perfeito, pois as crenças no mito da democracia racial e da mestiçagem encobrem e mascaram a brutalidade do cotidiano de preconceito e discriminação; muitos brasileiros aceitam a existência do racismo no país, mas alegam que eles mesmos não são preconceituosos nem discriminam racialmente. Nesse sentido, o silenciamento, o não dito e a não confissão são também fortes características do racismo à brasileira, pois "... além de matar fisicamente, ele [o racismo] alija, pelo silêncio, a consciência tanto das vítimas quanto da sociedade como um todo, brancos e negros" (p. 40).

Na perspectiva ocidental, o Brasil foi o último país do mundo a abolir o regime escravista. E, dentre os municípios brasileiros, Campinas aparece como a última cidade a acabar com o modo de produção baseado na exploração de mão de obra do negro escravizado. Podemos afirmar, então, que Campinas foi a última cidade do ocidente a cumprir com a abolição da escravatura. Os registros na história escravocrata do Estado de São Paulo apontam que até os anos de 1920 havia prática de escravidão em Campinas (Martins, 2017).

Nas primeiras décadas do século XIX, a população de escravos alcançou números expressivos quanto ao contingente populacional de Campinas: em 1829, a população de escravizados correspondia a $56,2 \%$ da população total do município (Martins, 2017) e, em 1836, a cerca de 60\% (Zero, 2009; Martins, 2017). De acordo com Eisenberg (1989 apud Zero, 2009), dados de 1874 apontam que a população escrava em Campinas era majoritariamente negra, o que corrobora com Martins (2017) que sinaliza a expressiva presença da população negra escravizada para a consolidação de Campinas no século XIX. Com a tentativa de branqueamento racial da população brasileira, Campinas, no pós-abolição, recebeu um 
contingente significativo de imigrantes europeus para trabalharem nas fazendas. Os negros que habitavam a cidade enfrentavam as mesmas problemáticas de total negligência e desassistência por parte do Estado. E pelo fato de Campinas ostentar da fama de maus-tratos contra os negros, mesmo aqueles não mais escravizados, muitos se aquilombaram em regiões mais afastadas ou passaram a ocupar áreas suburbanas da cidade (Martins, 2017). Lugares estes que hoje em dia são bairros periféricos de Campinas.

Parcamente se debate ou se produz sobre o assunto em Campinas. São poucos os espaços e instituições existentes na cidade que tenham como cerne a afirmação e valorização identitária de elementos da cultura dos povos negros ou que debatam e rememorem esse passado de expressiva presença da população negra, a exemplo da Casa de Cultura Fazenda Roseira, Casa de Cultura Tainã, Instituto Ibaô e Clube Machadinho.

Há um silenciamento gritante acerca do histórico escravista e uma negação de lugar do negro na cidade de Campinas, cujas marcas e símbolos perpetuam-se, ecoam e reeditam-se desde as relações socioeconômicas e raciais, com suas acentuadas desigualdades e iniquidades, até a sua organização arquitetônica, urbanística e espacial. Tais agenciamentos são fruto de um racismo velado e reverberam, também, no processo de saúde-doença da população negra - no que tange às especificidades e demandas de saúde dessa população e ao próprio acesso à saúde como direito básico - bem como na formação de subjetividades.

A partir de uma imersão numa Unidade Básica de Saúde (UBS) localizada num bairro periférico de Campinas, como psicólogo residente, foi perceptível a forte e expressiva presença de pessoas pretas e pardas como habitantes desse território e usuárias assíduas do serviço. Apesar dessa forte presença, não houvia discussões nem ações voltadas para as demandas específicas de saúde dessa população.

Levando em consideração o fato de o racismo ser o principal determinante no 
processo de saúde, adoecimento e morte da população negra em nosso país (Brasil, 2017), e as iniquidades produzidas pela discriminação racial e pelo silenciamento em torno dessa problemática, foi necessário pensar na criação de medidas de sensibilização e de aproximação dos profissionais dessa UBS com a população adstrita, a fim de romper o silêncio quanto às questões raciais. Foi criado um arranjo de promoção da saúde com foco na produção artística, estética, literária e religiosa de elementos da cultura do povo negro (Brasil, 2017). É reconhecido que essas ações formam uma estratégia potente de pertencimento e podem despertar processos de autoafirmação identitária e produção de identidade negra positiva (Cuti, 2017), fomentando, assim, a construção e o fortalecimento de vínculos entre a comunidade e a UBS, a fim de combater o racismo institucional na saúde.
Enquanto desdobramento do trabalho de conclusão da Residência Multiprofissional em Saúde Mental da Universidade Estadual de Campinas (UNICAMP), este artigo objetiva discutir tais questões suscitadas e apresentar, com base em um relato de experiência, o processo de construção e intervenção do projeto comunitário e intersetorial denominado "Dia do Orgulho Negro" numa unidade básica de saúde da periferia de Campinas, tendo em vista a aposta no contato, enaltecimento e resgate de elementos culturais do povo negro como mecanismo de promoção e produção de saúde. Destaca-se o potencial dessas ações como estratégias de pertencimento e autoafirmação identitária e fortalecimento de vínculos, visando à produção de identidade negra positiva e ao combate ao racismo institucional na saúde.

\section{Racismo institucional na saúde}


O racismo institucional desloca-se da dimensão individual e instaura a dimensão estrutural, correspondendo a formas organizativas, políticas, práticas e normas que resultam em tratamentos desiguais. Também denominado de racismo sistêmico, garante a exclusão seletiva dos grupos racialmente subordinados, atuando como alavanca importante da exclusão de diferentes sujeitos nesses grupos.

Estudos indicam diversos tipos de doenças, agravos e condições que acometem de forma mais prevalente a população negra brasileira, seja por fatores genéticos, hereditários, seja pelas desigualdades socioeconômicas (Werneck, 2016; Brasil, 2017). Os dados em saúde mental também chamam atenção: a população negra está mais vulnerável a transtornos mentais resultantes da exposição ao racismo e decorrentes do abuso de substâncias psicoativas, como o alcoolismo e a toxicomania, bem como apresentam maiores índices de sofrimento psíquico e figuram entre as maiores taxas de suicídio (Werneck, 2016; Amorim, 2018). Tais questões evidenciam a necessidade de planejar políticas, estratégias e ações que levem em consideração as demandas e especificidades de saúde dessa população.

Contudo, outros dados apontam diferenças abissais quanto ao acesso a bens e serviços de saúde e à qualidade dos serviços prestados para negros: menor taxa de consulta médica e odontológica ao ano, menos acesso a exames de mamografia e consultas prénatal, menos orientação sobre sinais e riscos na gravidez, menos acesso a medicamentos e internações, dentre outros (Brasil, 2017).

Esses dados tornam-se ainda mais preocupantes quando se considera que a população negra é maioria no Brasil, cerca de 55,8\% (IBGE, 2018), e representa também a maior parte dos usuários do SUS, cerca de 76\% (Amorim, 2018).

Essas iniquidades e o racismo institucional determinam marcadores importantes no processo de saúde, adoecimento e morte dessa população e tornam-se ainda mais graves quando a instituição não questiona os seus 
processos de trabalho nem se interroga de qual maneira a desigualdade racial atravessa as suas práticas.

\section{Violência, simbolização e transgeracionalidade}

Um aspecto das vivências de violências com que tomamos contato e que nos chamou bastante atenção foi a falta de reconhecimento do sofrimento advindo dessas situações - tanto pela vítima, como pela sociedade de maneira geral. Tivemos contato com crianças que muito cedo viveram diversas formas de violência, desde a privação de elementos básicos, como moradia, alimentação, escola, lazer etc., até a destituição do poder familiar em decorrência de situações mais extremas. Nesses casos, a falta de reconhecimento da dor subjetiva decorrente dessas vivências gerava ainda mais sofrimento, uma vez que, sem lugar de legitimação, era difícil inscrever tais eventos em uma cadeia simbólica de significações.

Segundo Eizirik (2006), a falta de simbolização de acontecimentos traumáticos pode ser um fator gerador de adoecimento psíquico, sendo o tratamento psicanalítico uma possibilidade de atuação na construção da integração psíquica e uma via para a representação simbólica desses eventos. Além disso, o autor destaca que essas dificuldades no processo de simbolização são frequentemente transmitidas através de gerações, podendo manifestar-se novamente em gerações futuras.

Benghozi (2000) mostra que a transmissão de conteúdos psíquicos se dá de uma geração para outra de maneira não linear e diferencia tais transmissões entre intergeracionais e transgeracionais. No primeiro caso, trata-se da transmissão de conteúdos psíquicos de uma geração para outra e, nesse trajeto, há elaboração de tais 
conteúdos pelos herdeiros que, por sua vez, os transmitem para uma terceira geração. Já no segundo caso, essa transmissão se dá de maneira não metabolizada e, desse modo, aquilo que diz respeito ao inominável é transmitido sem elaborações e simbolizações, gerando repetição entre as gerações. A transgeracionalidade se caracteriza, dessa forma, pela transmissão geracional de uma herança psíquica que é revivida por um indivíduo na atualidade, mas tem suas raízes em modos de funcionamento psíquico precedentes ao seu próprio nascimento. Esse fenômeno refere-se a conteúdos mentais não integrados, resultantes de vivências traumáticas que foram dissociadas e não simbolizadas através de palavras (Silva, 2005).

Há ainda que se considerar a abrangência na constituição das subjetividades coletivas quando nos referimos à produção e reprodução da violência. Nesse sentido, Souza (2015) nos aponta que, quando o Estado de Direito - que deveria ser capaz de sustentar um pacto social em que os interesses coletivos fossem prioritários em relação aos individuais - se perverte, ou seja, quando, ao invés de controlar a violência, é o próprio Estado que a produz através de suas ações ou pelo fracasso de tais ações, "a ideia de impunidade espalha-se pelo tecido social que infiltra o terreno das consciências individuais, generalizando-se numa descrença absoluta no poder do Direito e da Ética" (Souza, 2015, p. 89).

Birman (1994) afirma que as manifestações da violência na atualidade pressupõem o não reconhecimento da alteridade do outro, sendo este encarado como objeto de predação e gozo. É, no entanto, na possibilidade de representação simbólica que está a capacidade de se contrapor à necessidade de descarga direta das forças pulsionais agressivas, e nessa contraposição se daria a abertura para que o sujeito se constitua não como um projeto acabado, enrijecido e determinado por forças brutas, mas como um vir-à-ser.

Souza (2015) também nos mostra que é preciso que pensemos com base em análises e estratégias que articulem não só a dimensão macropolítica da violência, mas também a sua perspectiva 
micropolítica - como os processos de simbolização, desejos etc. -, uma vez que para trabalhar com essa temática não basta apenas considerar as representações conscientes. Desse modo, entendemos a intervenção com crianças e suas famílias - quando a transmissão do traumático não simbolizado se manifesta e reatualiza de extrema importância, sendo a psicanálise uma relevante ferramenta clínica por nos fornecer uma visão profunda e crítica da cultura e da saúde mental.

A seguir, relataremos experiências com atendimento de crianças vítimas de violências que ocorreram durante os dois anos de residência, exemplificando, assim, as manifestações macro e micropolíticas desse fenômeno, bem como possíveis formas de intervenção no âmbito do tratamento e prevenção de adoecimentos psíquicos decorrentes de situações de exposição à violência.

\section{Política Nacional de Saúde Integral da População Negra e apontamentos para o combate ao racismo na saúde}

Após muitas pressões da população negra e de movimentos sociais organizados, o Ministério da Saúde passa a reconhecer o racismo como principal determinante social em saúde para a população negra e institui, em 2009, a Política Nacional de Saúde Integral da População Negra - PNSIPN (Brasil, 2017; David, 2018).
A PNSIPN objetiva promover a saúde integral da população negra, de forma equânime, priorizando a redução das desigualdades étnico-raciais, o combate ao racismo e à discriminação nas instituições e serviços do Sistema Único de Saúde - SUS, buscando a superação das barreiras estruturais e cotidianas que 
incidem negativamente nos indicadores de saúde dessa população.

A PNSIPN deve ser encarada de maneira transversal e deve integrar as ações dos serviços que compõem os três níveis de assistência do SUS, assegurando: equidade racial e étnica em saúde, de maneira universal; prioridade na oferta de ações e de serviços; e assumir responsabilidade pela criação de mecanismos de promoção e produção de saúde integral para essa população (Brasil, 2017).

A PNSIPN dialoga bastante com as ideias preconizadas pela Política Nacional de Promoção da Saúde, uma vez que esta propõe ações pautadas por uma concepção holística de saúde, voltada para a multicausalidade do processo saúde-doença e que considere: a equidade, a fim de combater as injustiças sociais oriundas dos determinantes sociais; a intersetorialidade, para pensar o planejamento, a realização e avaliação de ações na perspectiva da integralidade do cuidado e da inclusão social; e a participação social, a fim de criar mecanismos que estimulem a corresponsabilidade, a autonomia e o empoderamento da comunidade envolvida (Brasil, 2010; Westphal, 2012).

Cabe aos profissionais da Atenção Básica a identificação de parceiros e recursos na comunidade que possam potencializar ações intersetoriais de relevância para a promoção da qualidade de vida da população, considerando as pessoas e populações em sua singularidade e inserção sociocultural (Brasil, 2012).

A Atenção Básica, portanto, é um campo fértil diante do grande desafio de enfrentamento do racismo institucional na saúde. Seu processo de trabalho, baseado na produção e sustentação de vínculo, sua capacidade de acolhimento e manejo de problemáticas sociais que incidem diretamente na qualidade de vida das pessoas, seu poder de mediação na intersetorialidade e a possibilidade de efetiva participação social e comunitária no SUS conferem à Atenção Básica a capacidade de fomentar ações de promoção da saúde com vistas ao enfrentamento das iniquidades em saúde vivenciadas pela população negra. 


\section{Psicologia e racismo}

Estruturada como uma ciência e profissão de base elitista, com preceitos higienistas e normativos, entre o final do século XIX e início do século $X X$, especialmente a partir dos estudos de Nina Rodrigues, a psicologia no Brasil posicionou-se como cúmplice do racismo, tendo produzido conhecimento que o legitimasse, validando cientificamente estereótipos infundados por meio de teorias eurocêntricas discriminatórias e por tomar por padrão uma realidade que não contemplava a diversidade étnico-racial brasileira (CFP, 2017).

O período entre 1930 e 1950 é caracterizado pelo debate da construção sociocultural das diferenças e pela desconstrução do determinismo biológico das raças nos estudos da psicologia e, de 1990 em diante, pelos estudos sobre branqueamento e branquitude (Santos, Schucman e
Martins, 2012). Atualmente o tema ascende institucionalmente (CFP, 2017).

Embora haja recomendações técnicas elaboradas pelos Conselhos da categoria, é perceptível o quanto a formação em psicologia, tendo em vista os atravessamentos do racismo no Brasil, é incipiente. Parece haver um não acolhimento por parte de muitas instituições de ensino da psicologia no que tange à indicação existente na Lei 10.639/03, sobre o ensino, para cursos superiores, da história e cultura dos povos africanos diasporizados.

Essa é mais uma faceta do racismo, que blinda as instituições de ensino superior em psicologia da responsabilidade de discutir questões raciais. Inclusive, mesmo com o advento das políticas de reparação e ações afirmativas na educação superior, a psicologia no Brasil segue formando, em sua maioria, pessoas brancas e de classe média (DIEESE, 2016). Vale ressaltar que são 
muitos desses profissionais que atuarão no SUS, cuja população negra representa a maioria dos usuários SUS-dependentes.

Schucman (2014) aponta que o fato de a grande maioria dos psicólogos e pesquisadores brasileiros serem brancos e socializados - entre uma população que se acredita desracializada - colabora para reificar a ideia de quem tem raça é o outro, além de manter a branquitude como identidade racial normativa. Sobre branquitude, a autora sublinha que o termo é entendido como uma posição em que pessoas brancas se ancoram em privilégios que foram construídos e mantidos sistematicamente na sociedade, como um privilégio racial, econômico e político, no que diz respeito

\section{Metodologia}

O interesse pela temática das relações raciais tomou particularmente o primeiro autor a partir da sua experiência de tornar-se negro, entendido como processo elaborativo e transformador, o que impulsionou a problematização das ao acesso a recursos materiais e simbólicos forjados pelo colonialismo e pelo imperialismo, que se mantém na contemporaneidade.

Veiga (2019) alerta para o perigo de a psicologia brasileira limitar-se às conceituações de homens-brancoseuropeus sobre saúde mental e sofrimento psíquico, os quais construíram conceitos para manejar o sofrimento psíquico apenas com foco nas subjetividades brancas: a ideia de subjetividade negra não aparece na grande maioria das graduações em psicologia, e um dos efeitos diretos disso é que pessoas negras podem ser vítimas de racismo pelos profissionais que deveriam acolhê-las.

questões raciais em sua atuação profissional.

Segundo Souza (1983), não nascemos negros, mas, sim, tornamo-nos negros. Para essa psicanalista baiana e negra, tornar-se negro é, acima de tudo, "a 
experiência de comprometer-se a resgatar sua história e recriar-se em suas potencialidades" (p. 18). E, nessa experiência pessoal, buscar formas de coletivizar o processo e ajudar na tomada de consciência do tornar-se negro para outras pessoas.

Sobre a experiência, Bondía (2002) nos conta que aquilo que acontece com o sujeito da experiência produz alguns afetos, deixa vestígios, inscreve algumas marcas e efeitos. Esse autor pontua também o efeito de formação ou de transformação a partir da experiência, na ordem do singular, do subjetivo. Além disso, Bondía ressalta que a força produtiva expressa através da experiência forma um saber e uma verdadeira práxis reflexiva entre teoria e prática, além de apontar que somente o sujeito da experiência pode impregná-la de sentido.

A UBS em questão localiza-se num bairro periférico do distrito norte de saúde do município de Campinas, uma região limite da cidade, fazendo fronteira com o município de Sumaré, e funciona pela lógica da Estratégia de Saúde da Família com apoio do Núcleo Ampliado de Saúde da Família - NASF.

A UBS atende usuários oriundos de cinco bairros, numa média de 16 mil pessoas, de todas as idades. São precárias as condições de vida de quem mora nessa localidade - muitas ruas sem asfalto, sem saneamento básico nem tratamento adequado para o lixo, sem infraestrutura de transporte adequado e opções públicas de lazer. Além disso, grande parte dessa população apresenta baixa escolaridade e vivencia violência doméstica e familiar. Não localizamos nas fontes oficiais a classificação por raça/cor da população adstrita, nem havia essa informação catalogada pela própria unidade.

A partir da nossa percepção, com o foco no quesito raça/cor dessa população assistida, destacamos a forte presença de pessoas pretas e pardas, muitas oriundas do nordeste brasileiro (ou com famílias com histórico de imigração) e refugiadas de outros países, especialmente do Haiti. Contudo, não havia práticas direcionadas às especificidades de saúde dessa população, o que se expressava em diferentes ações do cotidiano de 
trabalho: inexpressiva utilização da variável raça/cor nos prontuários; ausência de estratégias a fim de localizar e traçar ações de cuidado para pessoas com doença ou traço falciforme; supressão de inclusão da variável raça/cor quando na discussão de casos clínicos; falta de debates institucionais e comunitários com base na implementação da PNSIPN, dentre outros.

Para além disso, não havia debates nem questionamentos sobre o porquê de a maioria das participantes de grupos programáticos para pacientes com hipertensão arterial e diabetes eram de mulheres negras. Quanto a isso, Akotirene (2019) traz à baila o conceito de interseccionalidade, pensado como uma categoria teórica de análise que focaliza múltiplos sistemas de opressões interligados, em particular raça, gênero e classe, pontuando sobre como as condições estruturais do racismo, sexismo, capitalismo, patriarcado e violências correlatas se sobrepõem, discriminam e criam encargos singulares para as mulheres negras.
Algo precisava ser feito para problematizar essas questões. Contudo, era preciso uma certa cautela, a fim de não empurrar para o coletivo uma suposta demanda solitária, bem como lançar mão de uma estratégia cuidadosa para que qualquer provocação ou interrogação não fosse interpretada do lugar de uma mera denúncia dos silenciamentos e outros tipos de microagressões causadas pelo racismo, mas que fizesse sentido e ressoasse num tom construtivo tanto para o serviço quanto para a comunidade.

Foi então que, num determinado dia do grupo de promoção da saúde, uma participante (mulher negra e idosa, que desenvolvia uma ação voluntária num presídio masculino da região), sugeriu debatermos a questão da população carcerária no Brasil, questionando o porquê de a maioria ser de homens negros. A discussão ocorreu de forma intensa e foi perceptível que o grupo tinha necessidade de explorar mais aspectos dessa temática.

Cintra e Bernardo (2017) elucidam que a psicologia, inserida numa conjuntura social e comunitária, pode contribuir na 
perspectiva de tentar traduzir os anseios e necessidades expressas pelo território, colocando em palavras certas demandas e contribuindo no seu processo de busca por autonomia, autogestão e empoderamento, em consonância com aspectos sociais do cuidado.

Aproveitando o momento de sensibilização, foi sugerido para esse grupo e para a equipe da UBS uma proposta de realizar um evento de promoção da saúde cuja temática protagonizasse elementos da cultura negra e abrisse espaço para discussão do racismo. Houve aceitação unânime por esse grupo e por grande parte da equipe da UBS. A ideia foi aprovada também pelo Conselho Local de Saúde, uma vez que julgamos importante legitimar o projeto nessa instância de controle social.

Foram quatro meses de preparação e amadurecimento desse projeto, pensado de maneira intersetorial e com protagonismo da comunidade: educação, assistência social e equipamentos sociais do território, representantes do conselho local, moradores dos bairros e líderes comunitários. Foi formado o Núcleo Criativo, através do qual as decisões sobre o evento eram tomadas. As reuniões eram quinzenais, e passaram a ser semanais na proximidade do evento. Como ganho secundário dos encontros presenciais, percebemos estreitamento de vínculos entre todos os participantes envolvidos, experimentando outros tipos de relações e de poder contratual.

A proposta foi aprovada em um edital da Pró Reitoria de Extensão e Cultura da UNICAMP e o financeiro viabilizou a infraestrutura do evento. O nome do evento - Dia do Orgulho Negro - foi escolhido pelo núcleo criativo e o termo "orgulho negro" faz referência ao que objetivava com o projeto: demonstrar e celebrar um orgulho coletivo em torno de elementos da cultura do povo negro e valorizar a sua influência nos mais vastos processos de formação identitária e sociocultural do Brasil.

Através de levantamento feito pelo núcleo criativo, foram identificados elementos, grupos e expressões já existentes nos territórios ligados à cultura negra. Buscou-se, também, parcerias externas que atendessem às 
expectativas do projeto. 0 projeto resultou num grande festival, ocorrido na UBS e em seu entorno, totalmente gratuito e aberto, realizado no dia 24 de novembro de 2018, e contou com a participação média de 500 pessoas. A data foi escolhida tendo em vista a importância do "Novembro Negro", referência a atividades que inspiram a luta, resistência e revoltas do povo negro.

O Dia do Orgulho Negro teve as seguintes apresentações de grupos artísticos e culturais: Samba de Coco do Grupo Yiawarete; Tambor de Crioula do Grupo São Sebastião; Rap e Hip Hop com o grupo Arena do Rap; e Grupo de Capoeira Cordão de Ouro. O Grupo de Promoção da Saúde da UBS, composto sobretudo por mulheres idosas, também preparou uma apresentação de dança especialmente para o evento.

Houve tendas e barracas, gerenciadas por participantes do núcleo criativo e convidados, as quais ofertaram as seguintes oficinas e formações: contação de história com base na Tradição Griô; construção de Capulana; construção de boneca Abayomi; construção de turbantes; oficina de beleza e autocuidado com foco em peles negras. Como parte do projeto, um muro ao lado da UBS teve uma intervenção de grafite, tendo como inspiração o que ocorria no evento. Houve, também, uma tenda denominada "cinema temático", na qual eram exibidos curtas metragens e depoimentos de pessoas negras que figuraram protagonismo na luta por liberdade e justiça racial, além de especialistas que debateram a questão do racismo.

Foi montada uma exposição fotográfica com personalidades negras de diferentes épocas do Brasil, que contava com um elemento provocador, ao disponibilizar um espelho e questionar os expectadores com a frase "quem é você e qual a sua história?".

Na tenda do Conselho Local de Saúde, havia apoio e direcionamento jurídico para as questões relacionadas ao racismo e à discriminação religiosa. Essa ação ocorreu em parceria com o Centro de Referência Municipal em Direitos Humanos na Prevenção e Combate ao Racismo e à Discriminação Religiosa. Essa tenda era responsável, ainda, por 
esclarecer o público sobre de que forma o racismo institucional na saúde ocorre na realidade do Brasil, e apresentar a PNSIPN.

Houve também a presença do historiador campineiro Valdir Oliveira, que publicou um livro no qual narra a história do jovem negro escravizado Elesbão, considerado o primeiro a ser enforcado e decapitado publicamente em Campinas (Oliveira, 2016). Houve uma contação de história sobre a vida de Elesbão e sobre como negros escravizados eram fortemente castigados na cidade.

\section{Resultados e discussão}

Durante o evento, foi possível constatar uma presença expressiva da população negra moradora da região. Muitos foram com todos os membros da sua família, inclusive, convidaram parentes que não moravam na região ou mesmo na cidade.

Os comentários durante o evento deixavam escapar a sensação de pertencimento e de reconhecimento do que se via: um homem, com aparentemente 45 anos, revelou que estava morando em Campinas fazia mais de 20 anos e que não se lembrava da última vez que havia participado de uma roda de samba, recordando a sua infância e juventude na Bahia; em outro comentário, uma mulher de 30 anos afirmou que tudo aquilo fazia parte de quem ela era, mas que no dia a dia não havia como reconhecer aqueles elementos culturais no território e sentia falta disso. Nesse sentido, Cuti (2017) aponta que o processo de identificação do negro consigo mesmo perpassa também pela oportunidade de entrar em contato e se reconectar com elementos verdadeiramente culturais e artísticos dos seus antepassados.

Uma idosa de 68 anos pediu para ser fotografada junto com sua neta, de 3 anos. As duas ostentavam com orgulho seus turbantes confeccionados durante o evento. Ela pontuou que "não imaginava que o postinho poderia fazer um evento 
daquele tipo", fazendo referência à temática racial. Quanto a isso, David (2018) afirma que as atividades voltadas aos cuidados de pessoas e famílias nos serviços públicos, com o intuito de desnaturalizar o preconceito e gerar identificação negra positiva, são ações de prevenção e promoção de saúde que podem transformar os territórios qualitativamente.

Num dado momento, duas profissionais da assistência social conversavam com uma funcionária da escola municipal do território, todas do núcleo criativo. No diálogo, elas apontavam que inicialmente acreditavam que eventos assim eram de responsabilidade da área cultural, mas que, ao longo do processo e ao perceberem a grandiosidade do projeto, mudaram de opinião. Tavares (2014) destaca a necessidade de os diversos atores sociais e políticos criarem e sustentarem ações que possam dialogar sobre o processo de identidade negra positiva como elemento de autoafirmação e combate às diversas facetas do racismo.

A repercussão do evento foi avaliada como positiva e propositiva pelos seus participantes e pelo núcleo criativo. $\mathrm{Na}$ reunião intersetorial subsequente à realização do evento, a principal pauta foi a sua avaliação e possíveis desdobramentos. Como encaminhamento, pensou-se numa agenda de discussões e maior instrumentalização sobre a temática do racismo para, só então, o coletivo pensar em formas de intervenções sistemáticas de prevenção e combate ao racismo em todas as instituições que compõem a intersetorial.

As discussões sobre a temática do racismo também ganharam agenda em outros espaços da UBS. No Grupo Temático de Promoção da Saúde, que ocorre numa localidade do território externo às instalações da unidade, os participantes se autorizaram a relatar cenas de discriminação racial vivenciadas por eles, em diferentes momentos da vida. Passaram a adjetivar esses relatos como algo nocivo que, até então, não haviam percebido desse ângulo. Outros explanaram suas experiências, destacando o sofrimento e a vergonha que aquilo Ihes causava, mas que não sabiam como endereçar essa demanda 
de fala. Cuti (2017) destaca o quanto o racismo deixa marcas pungentes e que rememorar esse tipo de sofrimento dói, o que explica por que muitos negros negam que o racismo existe e os atinge. Mas, segundo esse autor, essa estratégia faz com que os negros fiquem ainda mais vulneráveis, tendo que elaborar constantemente essa experiência negativa.

Silva (2017) destaca ainda que, para muitas pessoas, o fato de ser e se assumir como negro é vivido com muita dificuldade, uma vez que foram introjetadas imagens negativas, produzidas pelo poder discriminatório, veiculadas pelos discursos acerca do que é ser negro. Assim, "torna-se muito difícil conviver com um corpo tido como feio, um cabelo por definição 'ruim', os lábios denominados beiços, etc." (Silva, 2017, p. 84).

Na reunião geral da UBS, ocorrida na semana seguinte à da realização do evento, foi feita uma avaliação por todos os profissionais. Alguns mantiveram-se em silêncio, mas todos aqueles que participaram da organização e/ou acompanharam o evento no dia pontuaram como positiva a sua realização. Uma enfermeira participante ativa do processo - propôs aproveitarem o espaço da reunião geral para discutir a PNSIPN e uma possível implementação na unidade. A proposta foi bem aceita e entrou na agenda de espaços formativos da UBS.

A tarefa de sensibilizar os profissionais para o perigo do silenciamento e da invisibilidade que o racismo institucional causa deve ser constante. Quanto a isso, David (2018) pontua que, quando os efeitos negativos do preconceito e da discriminação racial são considerados pelo profissional de saúde, o sujeito sente-se acolhido em seu sofrimento. 0 autor considera que, para isso ocorrer, o profissional deve dispor de escuta sensível quanto às dinâmicas das relações raciais, além de formação permanente para o exercício de um cuidado qualificado perante os possíveis sofrimentos provenientes dos preconceitos raciais.

Também posteriormente à realização do evento, alguns Agentes Comunitários de Saúde confessaram que muitas vezes não preenchiam a lacuna destinada para o 
quesito raça/cor na ficha de cadastro dos pacientes por não se sentirem confortáveis para perguntar com qual cor de pele o usuário se autodenominava, alegando não saberem como abordar a temática bem como "um receio de retaliação por má interpretação das pessoas". Para perceber o descuido com a coleta, a discussão e a análise do quesito raça/cor nos equipamentos de saúde, é preciso não apenas estar consciente da existência do racismo, mas estar sensível, disponível e capacitado tecnicamente para o reconhecimento das diversas formas pelas quais o racismo se apresenta, assim como para intervir nos possíveis efeitos/sintomas psicossociais que podem causar (Monteiro, 2012).

\section{Considerações finais}

É preciso empenho coletivo na tarefa de enfrentar os efeitos do racismo nas instituições de saúde. Somente pelo reconhecimento da sua existência é que poderemos efetivamente combatê-lo. Afinal, não podemos confrontar aquilo que silenciamos, negligenciamos ou invisibilizamos. Como já discutido, o silêncio é cúmplice das violências raciais; permanecer em silêncio é ser conivente, em alguma medida.

Há carência de estudos, relatos de experiências e, sobretudo, incentivos públicos às iniciativas coletivas de combate ao racismo institucional na saúde. Faz-se necessário instigar e suscitar mais reflexões acerca dessa questão, tanto na academia quanto no cotidiano dos serviços. As instituições de formação profissional - seja da psicologia seja de outros núcleos - e os serviços de saúde não podem mais se esquivar do compromisso e da responsabilidade de estarem atentos aos efeitos do racismo institucional. Precisamos, cada vez mais, combater a construção de representações negativas dos negros e fomentar identidade racial positiva, a fim de construir novos modos de 
subjetivação e de relações pautadas numa equidade racial.

É necessário, também, discutir o racismo com base na branquitude e os seus privilégios. Caso não façamos isso, corremos o risco de permanecer com o pêndulo da balança das discussões raciais desequilibrado e sempre naturalizar os privilégios de um grupo em detrimento do outro. Afinal, ser antirracista é também reconhecer que o racismo foi criado e é mantido sistematicamente pela branquitude.

Ser antirracista é defender indubitavelmente o SUS, a democracia, a ideia da saúde como direito básico e universal, o princípio da equidade e todos os dispositivos que tragam em seu cerne a defesa das populações historicamente mais vulneráveis. Assumir uma postura antirracista requer responsabilizar-se ativamente por uma mudança individual, contudo, sem perder de vista que nem todos estão no mesmo nível de tomada de consciência no processo de tornar-se negro ou de reconhecer e se interrogar acerca dos privilégios da branquitude. $\mathrm{O}$ antirracismo deve estar principalmente no coletivo, na forma de uma postura cooperativa.

O Dia do Orgulho Negro pode ser compreendido como uma medida antirracista cooperativa, tendo em vista os efeitos gerados nas instituições e nos participantes desse processo. Interpelar processos de trabalhos, renegar o discurso meritocrático quanto aos lugares de privilégio institucional ocupados pela branquitude, suscitar debates em torno das questões raciais e fomentar espaços formativos fazem parte de uma postura antirracista com objetivo de atingir uma coletividade.

O Dia do Orgulho Negro instaurou nessa UBS uma mudança no processo de trabalho mais sensível às questões raciais. Os Agentes Comunitários de Saúde, a maioria de pessoas negras, passaram a interpelar com mais tranquilidade os usuários acerca da sua raça/cor e a preencher esse item na ficha cadastral. Grande parte dos profissionais começou a demarcar a raça/cor dos usuários quando apresentavam uma discussão de caso. A coordenação da UBS sublinhou o Dia do Orgulho Negro como evento fixo no calendário anual de 
atividades de promoção da saúde bem como apresentou essa experiência para outros equipamentos da Atenção Básica do município. Além disso, percebemos um estreitamento na relação entre os profissionais e usuários, com maior frequência destes na unidade e nos espaços de controle social, bem como na proposição de novas atividades, com uma participação ativa e implicada, muitas vezes rememorando essa experiência e destacando o seu pertencimento racial.

\section{Referências}

Akotirene, C. (2019). Interseccionalidade. In Ribeiro, D. (Coord.), Feminismos plurais. São Paulo: Sueli Carneiro: Pólen.

Almeida, S. L. de. (2019). Racismo estrutural. In Ribeiro, D. (Coord.), Feminismos plurais. São Paulo: Sueli Carneiro: Pólen.

Amorim, C. C. (2018). População negra e saúde: por que debater? In Revista Construção. Recuperado em 3/jul./2020, em http://revistaconstrucao.org/saude-publica/populacao-negra-e-saude-porque-debater/

Bondía, J. L. (2002). Notas sobre a experiência e o saber da experiência. Universidade de Barcelona, Espanha. (Geraldi, J. W., Trad.). Revista Brasileira de Educação, 19, São Paulo.

Cintra, M. S \& Bernardo, M. H. (2017). Atuação do psicólogo na atenção básica do SUS e a psicologia social. Psicologia: ciência e profissão, 37, 4. ed. 883-896, Brasília, DF: CFP. 
Conselho Federal de Psicologia (2017). Relações Raciais: Referências técnicas para atuação de psicólogas/os. CREPOP, Brasília.

Cuti, L. S. (2017). Quem tem medo da palavra negro. In Kon, N. M, Silva, M. L. da, \& Abud, C. C (Orgs.). O racismo e o negro no Brasil: questões para a psicanálise. São Paulo: Perspectiva.

David, E. de. C. (2018). Saúde mental e racismo: a atuação de um Centro de Atenção Psicossocial II Infanto-juvenil. Dissertação de mestrado. Pontifícia Universidade Católica de São Paulo, São Paulo.

David, E. de. C, \& Silva, L. A. de. A. (2018). Territórios racializados: a Rede de Atenção Psicossocial e a Política Nacional de Saúde Integral da população negra. In. Silva, M. L; Farias, M; Ocariz, M. C., \& Stiel Neto, A. S. (Orgs.). Violência e sociedade: o racismo como estruturante da sociedade e da subjetividade do povo brasileiro: São Paulo: Escuta.

Departamento Intersindical de Estatística e Estudos Socioeconômicos (2016). Levantamento de informações sobre a inserção dos psicólogos no mercado de trabalho brasileiro. Contrato de Prestação de Serviços DIEESE e Conselho Federal de Psicologia, São Paulo.

Instituto Brasileiro de Geografia e Estatística (2010). População do município de Campinas segundo o quesito raça/cor. Censo Demográfico de 2010. Rio de Janeiro: IBGE.

Instituto Brasileiro de Geografia e Estatística (2018). Pesquisa Nacional por Amostra de Domicílios Contínua. Rio de Janeiro: IBGE.

Martins, A. R. (2011). Requalificação urbana: a Fazenda Roseira e a comunidade Jongo Dito Ribeiro. Dissertação de mestrado. Pontifícia Universidade Católica de Campinas, Campinas. 
Martins, A. R. (2017). Matriz africana em Campinas: territórios, memória e representação. Tese de doutorado, Programa de pós-graduação em urbanismo. Pontifícia Universidade Católica de Campinas, Campinas.

Ministério da Saúde. (2010). Política Nacional de Promoção da Saúde. Secretaria de Vigilância em Saúde, Secretaria de Atenção à Saúde. 3. ed. Brasília, DF: Ministério da Saúde.

Ministério da Saúde. (2012). Política Nacional de Atenção Básica. Secretaria de Atenção à Saúde. Departamento de Atenção Básica. Brasília, DF: Ministério da Saúde.

Ministério da Saúde. (2017). Política Nacional de Saúde Integral da População Negra. Secretaria de Gestão Estratégica e Participativa. Departamento de Apoio à Gestão Participativa e ao Controle Social, 3. ed. Brasília, DF: Ministério da Saúde.

Monteiro, M. do C. S. (2012). Desafios da inclusão da temática étnico-racial na Educação Permanente em Saúde. In Batista, L. E; Werneck, J., \& Lopes, F. (Orgs.). Saúde da população negra, 2. ed. rev. e ampl. Brasília: Associação Brasileira de Pesquisadores Negros.

Munanga, K. (2017). As ambiguidades do racismo à brasileira. In Kon, N. M; Silva, M. L. da, \& Abud, C. C (Orgs.). O racismo e o negro no Brasil: questões para a psicanálise. São Paulo: Perspectiva.

Oliveira, V. (2016). Elesbão. Campinas: Gráfica e Editora 57.

Schucman, L. V. (2014). Sim, nós somos racistas: estudo psicossocial da branquitude paulistana. Psicologia \& Sociedade, 26(1), 83-94. https://doi.org/10.1590/S0102-71822014000100010 
Silva, M. L. da. (2017). Racismo no Brasil: questões para psicanalistas brasileiros. In Kon, N. M; Silva, M. L. da, \& Abud, C. C (Orgs.). O racismo e o negro no Brasil: questões para a psicanálise. São Paulo: Perspectiva.

Sousa, N. S. (1983). Tornar-se negro: as vicissitudes da identidade do negro brasileiro em ascensão social. v. 4, Rio de Janeiro: Edições Graai, Coleção Tendências.

Tavares, N. de O. (2014). Reconhecimento e ressignificação: identidade positiva e juventude negra. Dissertação de mestrado. Universidade Federal de Minas Gerais, Belo Horizonte.

Veiga, L. (2019). Descolonizando a psicologia: notas para uma Psicologia Preta. Fractal: Revista de Psicologia, 31, 244-248. doi: https://doi.org/10.22409/1984-0292/v31i_esp/29000

Werneck, J. (2016). Racismo institucional e saúde da população negra. Saúde e Sociedade, 25(3), 535-549. https://doi.org/10.1590/s0104-129020162610

Westphal, M. F. (2012). Promoção da saúde e prevenção de doenças. In Campos, G. W. de. S, M, M. C. de. S., Akerman, M., Drumond Júnior, M. \& Carvalho, Y. M. de (Orgs.). Tratado de Saúde Coletiva. 2. ed. São Paulo: Hucitec. Zero, A. H. (2009). Escravidão e liberdade: as alforrias em Campinas no século $X I X$. Tese de doutorado. Instituto de Economia, Universidade Estadual de Campinas, Campinas.

Recebido em: 21/08/2020 Aprovado em: $15 / 12 / 2020$ 